Frontiers in Heat and Mass Transfer

\title{
TRACE SPECIES AND AIR POLLUTANT TRANSPORT IN GREEN FACADES: A VERNONIA ELAEAGNIFOLIA CASE STUDY FOR A BUILT ENVIRONMENT
}

\author{
Jacob Thottathil Varghese ${ }^{\mathrm{a},{ }^{*}}$ Sat Ghosh ${ }^{\mathrm{a}, \mathrm{b}}$ \\ ${ }^{a}$ VIT University, Vellore, Tamil Nadu, India - 632014 \\ ${ }^{b}$ University of Leeds, United Kingdom
}

\begin{abstract}
Nature has its own astonishing capabilities to cleanse polluted environment. Living green drapes on buildings look elegant providing sustainable solutions in congested metropolises. VIT University promotes green values within the country. The walls of a subway connecting the main campus and hostel premises are draped with Vernonia elaeagnifolia, which was found to be efficient in capturing vehicular pollution. An experimental study established deposition patterns of pollutants. Thereafter, diffusive uptake modelling elucidated the mechanistic details of mass transport through the plant tissues. It is expected that the results of this paper will promote the use of green facades within built environment.

Keywords: Air pollution, Atmospheric cleansing, Energy efficiency, Green façades.
\end{abstract}

\section{INTRODUCTION}

Air pollutants pose a high risk for humans and the environment, and this gaseous pollution is one of the major environmental problems facing modern society. To a certain extent, green foliage around us can alleviate these environmental issues. The transient diffusion of nutrients (Carbon and Oxygen) and gaseous pollutants (mainly oxides of nitrogen and sulphur) into plant bodies occur through their stomatal pores-an essential connecting link between the plants' internal air spaces and the external atmosphere (Taiz and Zeiger, 2002). The most important characteristic of the stomata is that they can even change the aperture size to regulate gas exchange. A major portion of the plants' uptake, including the nutrient minerals and pollutants, is absorbed from the soil through the roots (Taiz and Zeiger, 2002). Though a few of the trace minerals - Boron (B), Chlorine $(\mathrm{Cl})$, Manganese $(\mathrm{Mn})$, Iron $(\mathrm{Fe})$, Zinc $(\mathrm{Zn})$, Copper $(\mathrm{Cu})$, Molybdenum $(\mathrm{Mo})$ and nickel $(\mathrm{Ni})$ are involved in plant metabolism to stimulate plant growth (Arnon and Stout, 1939; Ute Kramer, 2012; Barker and Pilbeam, 2007), they are not essential-some are essential only for certain plant species, and under specific conditions are also beneficial elements (Konrad et al., 2001; Jeff and Wayne, 2010; Owen and David, 1989; Bhargava, 2008; Muralikrishna, 1997). On the other hand it was reiterated that emissions from the combustion of fossil fuels contributed considerable amounts of NOx into the atmosphere (Blumberg et al., 2003).

In this paper, we show results from a living green wall draped with Vernonia elaeagnifolia as part of a green initiative. The analysis showcases the versatility of Vernonia elaeagnifolia as a façade drapenot only does it lend a verdant ambience to an otherwise drag Concreted wall, it also substantially absorbs vehicular as well as industrial pollution from Vellore's noxious atmosphere. The prevailing wind speeds and directions over Vellore are summarized below. Vellore sees south-west winds from June to September, while dominantly north east winds exist in the monsoon period from October to December. One can observe that during the summer and winter, Wall 2 and Walls 1, 4, 3 respectively receive air borne pollution. The region is therefore an interesting base case for studies on transient uptake of air pollutants by green walls.

Considering the rapidly increasing industrial activity in India, air pollution levels in the country are bound to be on the rise. Add to it the noxious exhaust of a growing number of automobiles; the issue becomes one that needs to be tackled immediately. It is expected that this study will encourage the use of extended green façades to regulate air pollution. The use of such solutions in India's congested metropolitan cities would be particularly interesting.

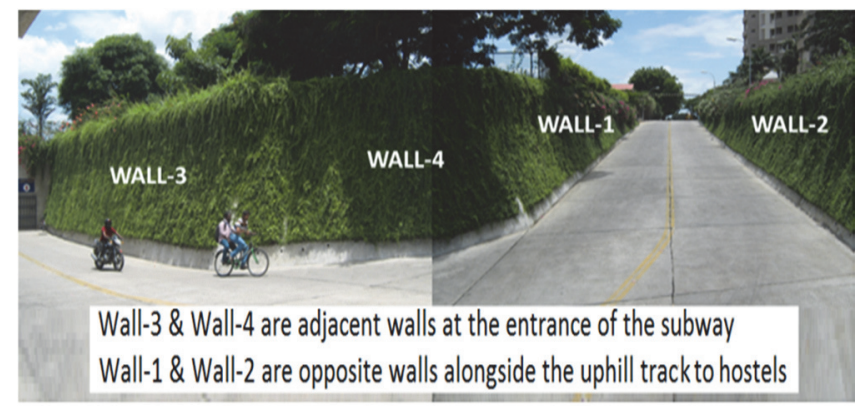

Fig. 1 The subway at VIT University, Vellore, Tamil Nadu, India draped with Vernonia elaeagnifolia creeper

Table 1 Subway wall characteristics

\begin{tabular}{|l|l|l|l|l|}
\hline \multirow{2}{*}{$\begin{array}{l}\text { Subway } \\
\text { walls }\end{array}$} & \multirow{2}{*}{$\begin{array}{l}\text { Wall } \\
\text { orientation }\end{array}$} & $\begin{array}{l}\text { Area draped } \\
\text { by the } \\
\text { facade }\end{array}$ & $\begin{array}{l}\text { Adopted terminology } \\
\text { for the samples collected } \\
\text { on 29 }\end{array}$ \\
\cline { 3 - 5 } & & $\begin{array}{l}\text { Exterior } \\
\text { layer }\end{array}$ & $\begin{array}{l}\text { Interior } \\
\text { layer }\end{array}$ \\
\hline WALL-1 & $22.5^{0}$ South & $124.315 \mathrm{~m}^{2}$ & WALL-1e & WALL-1i \\
\hline WALL-2 & $22.5^{0}$ North & $157.093 \mathrm{~m}^{2}$ & WALL-2e & WALL-2i \\
\hline WALL-3 & $22.5^{0}$ West & $158.349 \mathrm{~m}^{2}$ & WALL-3e & WALL-3i \\
\hline WALL-4 & West & $48.943 \mathrm{~m}^{2}$ & WALL-4e & WALL-4i \\
\hline
\end{tabular}


The subway has four walls, fully draped with the green creeper, covering a total area of approximately $488 \mathrm{~m}^{2}$. Whilst the first two walls (WALL-1 \& 2) are located opposite to each other, the other two walls (WALL-3 \& 4) are respectively the tallest and the smallest with WALL-1, $3 \& 4$ as the adjacent walls (Fig. 1). Table 1 represents the elaborated wall characteristics adopted throughout the analysis

\section{COLLECTION AND INITIAL PREPARATION OF SAMPLES}

On each of the walls, a two layer analysis is conducted to quantify the concentrations. The leaf samples are collected from both the exterior and interior layers of all the four walls, altogether 8 samples, each sample having $12-15$ leaves. To maintain the homogeneity of each sample, the leaves are plucked from six different locations which are uniformly distributed along the entire length of the respective draped walls. The collected samples are oven dried at $95^{\circ} \mathrm{C}$ for a time span of 24 hours (Hot Air Oven - AUSCO, cubical chamber size $350 \mathrm{~mm}$, dual shelf, 1200 watts), stored in a desiccator to prevent moisture infiltration. It is then fine-powdered using mortar pestle and preserved for further procedures. One gram from each powdered sample is then properly mixed in a conical flask with $100 \mathrm{ml}$ distilled water. After a settling time of another 24 hours, the solution is filtered using Whatman 42 filter paper for physic-chemical analyses.

The prepared samples from each wall are then analysed using standard procedures to quantify the concentrations of Sulphates, Nitrates, Chlorides, Ammonia Nitrogen and Manganese (Bhargava, 2008; Muralikrishna, 1997).

\subsection{Analysis of Sulphates $\left(\mathrm{SO}_{4}{ }^{2-}\right)$ and Nitrates $\left(\mathrm{NO}_{3}{ }^{-}\right)$}

Whilst the turbidity method is employed to determine the Sulphate concentration (the prepared sample is stirred well for a minute after mixing with the conditioning agent and barium chloride crystals), the concentration of Nitrate is calculated using UV spectrophotometric analysis by setting the absorbance range at $220 \mathrm{~nm}$ (Make: Hitachi U$2800, \lambda: 190-1100 \mathrm{~nm}$, spectral bandwidth $1.5 \mathrm{~nm}$, wavelength scan speed-10, 100, 200, 400, 800, 1200, $2400 \& 3000 \mathrm{~nm} / \mathrm{min}$, baseline stability- $0.0003 \mathrm{Ab} / \mathrm{h}$, silicon photodiode detector).

Sulphate, one of the major constituents of natural water is precipitated in hydrochloric acid medium with $\mathrm{BaCl}_{2}$ to form $\mathrm{BaSO}_{4}$. The turbidity of $\mathrm{BaSO}_{4}$ suspension is measured by pouring the prepared solution into the glass cell of digital turbidity meter (Model $331 \mathrm{E}$, deep vision, $30 \mathrm{~mm}$ flat bottom Test Tube, $3^{1 / 2}$ digit LED display, range $0-1000 \mathrm{NTU}$, photo cell/photo diode detector system, 6V Tungsten Lamp, AC $230 \mathrm{~V} \pm 10 \%, 50 \mathrm{~Hz}$ ). A calibration plot is prepared with a standard sulfate solution, made in the range of $0-40 \mathrm{mg} / \mathrm{L}$ of Sulphate. To establish the concentration of Sulphates in the analyzed samples, the calibration chart is plotted with the known Sulphate concentration against the measured turbidity values.

\subsection{Analysis of Chlorides $\left(\mathrm{Cl}^{-}\right)$and Ammonia Nitrogen $\left(\mathrm{NH}_{3}-\mathrm{N}\right)$}

The titration method is adopted to find the concentration of chlorides and ammonia nitrogen. Chlorides are found by Mohr's or Argentometric method, based on the fact that in a solution containing both chlorides and chromates, silver reacts first with chlorides and then with chromates. The prepared sample is initially mixed with a few drops (2-3 drops) of potassium chromate indicator and finally titrating with standard silver nitrate $(0.0141$ Normal $)$ as the titrant until the yellow colour gives way to brick red. To comment on the concentration of Ammonia Nitrogen $\left(\mathrm{NH}_{3}-\mathrm{N}\right)$, the sample is mixed with both phosphate buffer and boric acid solution (ammonia can be trapped in weak boric acid), followed by a few drops of methyl orange indicator - titrating until yellow, with standard $0.02 \mathrm{~N}$ sulphuric acid (Bhargava, 2008; Muralikrishna, 1997).

\subsection{Analysis of Manganese (Mn)}

The Manganese concentrations in the prepared samples are established by Persulphate spectroscopic method. The standards are prepared from $1 \mathrm{mg}$ and made up to $5 \mathrm{mg}$ of the known concentration of Manganese. Thence both the standards and the samples follow the same procedural line - mix the required amount of sample in $250 \mathrm{ml}$ of Erlenmeyer conical flask with $5 \mathrm{ml}$ of special reagent $\left(\mathrm{HgSO}_{4}\right.$, Phosphoric acid and Silver nitrate) and a drop of hydrogen peroxide, further dilute to $90 \mathrm{ml}$ with de-ionized water. A spectrophometric analysis, maintaining the absorbance range at $525 \mathrm{~nm}$, followed by a standard calibration plot quantifies the concentration of Manganese present in the analyzed samples.

Fig. 2 represents the concentration of sulphates, nitrates, chlorides and ammonia nitrogen over the exterior and interior layers of the subway walls draped with Vernonia elaeagnifolia creeper - the average value of chloride concentration stands highest $(350 \mathrm{ppb}-$ $440 \mathrm{ppb}$ ) among the others. Other than the natural sources, chlorine enters the soil mainly through irrigation. The draped creepers are well irrigated and nurtured, thus causing a huge rise in chloride concentration.

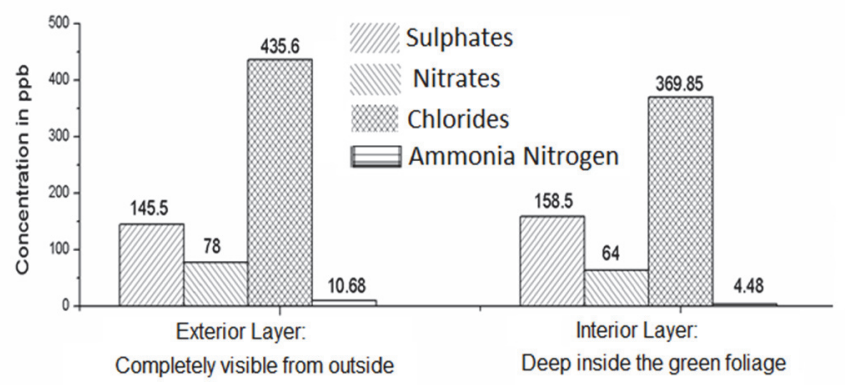

Fig. 2 A detailed plot to quantify the concentrations of sulphates, nitrates, chlorides, NH3-N and Mn.

Since these creepers are grown inside the premises of a Technological University, there is little chance for the presence of waterlogged acid soils, as usually found near industrial several estates, to promote heavy manganese concentration in plant leaves - through the analysis it has been established that there are no detectable traces of manganese present in the green foliage (Fig. 2), though manganese serves as a micronutrient for photosynthesis (Lewcock and Harriman, 2012). Among the analyzed constituents (excluding manganese), the concentration of ammonia nitrogen is the least (less than $15 \mathrm{ppb}$ ), the predominant reasons being the less usage of NPK fertilizers and little use of any hazardous pesticides.

Apart from chlorides, the main traces present in the samples are the sulphates (80ppb to 208ppb) and nitrates (40ppb to 108ppb). The average values of sulphate concentration on both the exterior and interior layers of the subway walls are almost double than the respective nitrate concentrations. Since the vehicular emissions contain more NOx than SOx (Blumberg et al., 2003), the bulk of the sulphate concentration came through the roots than the atmosphere. As the outer foliage is pruned periodically (every 2 months), there always exist newer leaves. Hence the sulphate concentration is lesser on the exterior foliage than the deep interiors. On WALL-3 \&4, the sulphate concentration of the exterior layers is found to vary between $6 \%$ (minimum)- 52\% (maximum) than the interior foliage; particularly it is halved on WALL-4. Contrary is the case with nitrates, the exterior concentrations are at higher side than the interior - interestingly doubled on WALL-4, because, though the entire subway has a modest 
gradient, the vehicles plying from the academic campus to the hostels have to negotiate a sharp turn near WALL-4, spewing more exhaust gases which are directly absorbed by the outer leaf layer (Fig. 3).

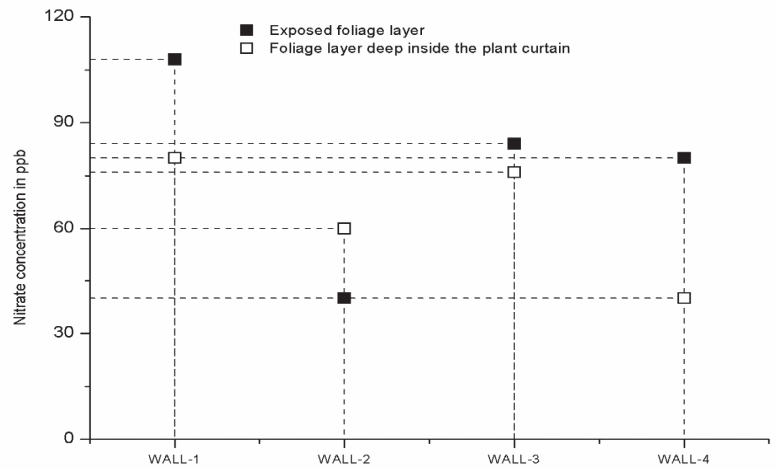

Fig. 3 Comparing the nitrate concentration of both exposed and interior foliage.

From the preceding analysis it is clear that soil mediated pathways contributed to the abundance of the trace species considered in this study-the only exception is the presence of nitrates. Vehicular emissions in the subway contributed to the overall nitrate concentration.

It reiterates the need for the foliage to be exposed to these pollutants to efficiently cleanse the atmosphere. Despite the turbulence and heavy vehicular emissions near WALL-4, the larger availability of mixing volume alleviates the pollutant concentration to a greater extent. Hence the nitrate concentration on both the exterior and interior layers of WALL-4 is lesser by $3 \%(\min )-50 \%(\max )$ than on WALL-3 and WALL-1.A CFD analysis was performed to analyze the uptake rates of nitrates by the foliage. Individual stomata were modeled to intricate geometric and biophysical detail with a blockwise uniform finite difference grid governed by multicomponent Fickian diffusion equations. The model incorporated the Lenard-Jones method for calculating binary diffusivities between the participant gases, which included the effects of dipole moment. Breakdown of gases into ions in the apoplastic region was also modeled.

\subsection{Nitrate Absorption}

Oxides of nitrogen are a major component of automobile exhaust. Experimental analysis of the air quality of the underpass revealed the ambient nitrate concentration to be approximately $10 \mathrm{ppb}$. Using this boundary condition, the deposition velocity of nitrates onto the species in question was calculated from the CFD model. This was determined to be $1.9 \mathrm{~cm} / \mathrm{s}$ for open pores and $0.81 \mathrm{~cm} / \mathrm{s}$ for closed pores. The variation of nitrate concentration with stomatal depth is shown in Fig. 4.
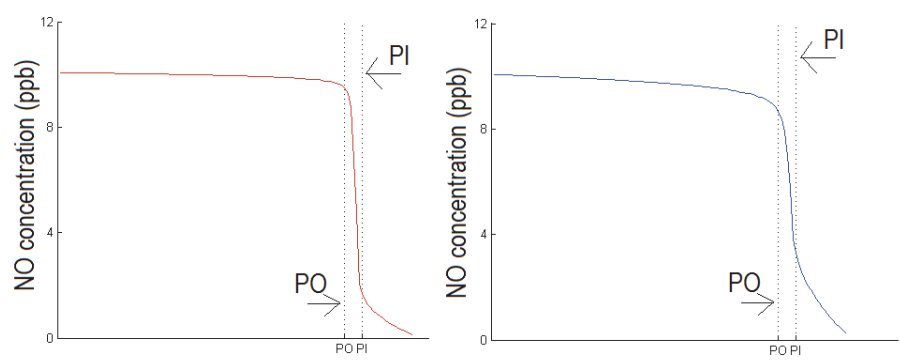

Fig. 4 (a) NO concentration on central axis for closed pores (b) NO concentration on central axis for open pores
With the above main conclusions with regards to nitrate uptake, we now seek to explore the mechanistic details of sulphate uptake through time dependent mass transfer calculations. While the overall concentrations were estimated experimentally in the preceding section, it is interesting to understand the absorption pattern more quantitatively through deposition velocities obtained from CFD modelling. This we now undertake.

\section{MODELLING THE UPTAKE OF SULPHATES OVER A FAÇADE DRAPED WITH VERNONIA ELAEAGNIFOLIA}

There exist two major sources of sulphur supply to a plant: the first involves the uptake of sulphates by roots from the soil, and the second is through the diffusion-mediated transport of gaseous $\mathrm{SO}_{2}$ into plant leaves through the stomata. The majority of sulfate reduction reaction in leaves derive their starting substrate from the gas reservoir of $\mathrm{SO}_{2}$. Therefore, it is essential to make an estimate of the rate at which gaseous Sulphur dioxide is absorbed by the green vegetation.

The net rate of change in sulphur content of the leaf is the difference between the rate of uptake (first bracketed term in Equation 1) and the rate of assimilation (second bracketed term in Equation 1). The rate of uptake depends inversely on the concentration of sulphate in the leaves (Cardenas et al., 1997). The assimilation of absorbed sulphate is brought out by a sequence of biochemical reactions; therefore, apart from the sulphate levels of leaves, the rate of assimilation also depends on the rate constants of each of these reactions.

$\rho_{I I} V_{I I} \frac{\partial s}{\partial t}=\left\{\rho_{I} V_{I} s_{g} \cdot\left(k_{c}-b s\right)\right\}_{d a y}-\left(\rho_{I I} V_{I I} k_{a} s\right)_{\text {day,night }}$

The density-volume product in every term is to convert the concentration into mass balance. The subscript-I is for the passageway and subscript -II for the region within the leaves on the vegetated wall. The control volume of the region $\mathrm{I}$ is the volume of a cuboid of dimensions $100 \mathrm{~m} \times 3 \mathrm{~m} \times 2 \mathrm{~m}\left(\mathrm{~V}_{\mathrm{I}}=600 \mathrm{~m}^{3}\right)$. For region II, the control volume is calculated as

$V_{I I}=L A_{w} d$

Here $\mathrm{L}$ is the leaf area index of the façade (measured as 3.8), the wall area, $A_{w}$ (measured as $3 \times 100=300 \mathrm{~m}^{2}$ ) and ' $\mathrm{d}$ ' is the average leaf thickness. Measurements yielded d $=0.3 \mathrm{~mm}$. $V_{I I}$ is then calculated to be $0.741 \mathrm{~m}^{3}$. The amount of sulphur present in the leaf is ' $\mathrm{s}$ ', and $S_{g}$ is the concentration of $\mathrm{SO}_{2}$ in the atmosphere. The removal rate for stomatal pores is $\mathrm{k}_{\mathrm{c}}$ and the assimilation rate of sulphur inside the leaf is $\mathrm{k}_{\mathrm{a}}$.

We will follow the following order of study for the absorption modeling. Firstly, we define the uptake rate of gaseous $\mathrm{SO}_{2}$ from the atmosphere into the leaves. For this purpose, cleansing rate values determined using numerical simulations of individual stomata will be used. Secondly, we summarize the pathway of sulphur assimilation and determine the rate constants of the reactions involved. This will give us the value for the rate of assimilation (k). Finally, shall we shall formulate the diurnal variation in sulphur concentration and correlate it to the rate of absorption of $\mathrm{SO}_{2}$ from the underpass.

A recent study was aimed at the quantification of the deposition velocity of this gas with the assumption of a perfect chemical sink for the absorbed $\mathrm{SO}_{2}$ (Joshi and Ghosh, 2014). Individual stomata were modeled with a deep level of physical detail. The chemical dissociation of $\mathrm{SO}_{2}$ into bisulphite ions was also included in the numerical model. With a perfect sink assumption, typical removal rates for open stomatal pores $(\mathrm{kc})$ were found to be of the order of $2.17 \mathrm{e}^{-6}$ during the day and $2.54 \mathrm{e}^{-7}$ at night. This is multiplied by 0.5 to account specifically for the amount of sulphur removed from the air and added to the leaf. Thus, $\mathrm{kc}=1.085 \mathrm{e}^{-6}$ (day) and $1.27 \mathrm{e}^{-7}$ (night). In short, the only 
takeaways from Joshi and Ghosh, 2014, are the values of the removal rates. All the subsequent analysis shown relates to the most recent calculations and are now described.

The velocity of a catalyst-driven reaction can be calculated from the Michaelis-Mentel equation

$$
V=V_{\max } \frac{A P S}{\left(A P S+K_{m}\right)}
$$

The maximum reaction velocity assumes an infinite source of the substrate (i.e. called ATP SulphurylaseAPS) as compared to the enzyme APR. The values of this velocity vary over a wide range. We use a authentically reported value of $40 \mu \mathrm{mol} \mathrm{min}^{-1}$ (Suter et al., 1999). $\mathrm{K}_{\mathrm{m}}$ is a measure of the catalyst's affinity for the substrate - lower the $\mathrm{K}_{\mathrm{m}}$ value, the higher is its affinity, and the reaction is accelerated further. The $K_{m}$ value for this reaction is $6.5 \mu \mathrm{mol}$ (Suter et al., 1999).

The concentration for APS can be obtained as a function of the super concentration by using the equilibrium $-\mathrm{K}_{\mathrm{eq} 1}=150, \mathrm{~K}_{\mathrm{eq} 2}=9 \mathrm{e}^{-8}$ ) (Schuermann and Brunold, 1980; Gay et al., 2009; Haensch et.al., 2006). Therefore, the value of APS is arrived as

$A P S=9 \times 10^{-8} \boldsymbol{s}$

A comparison of the two terms in the denominator of Equation 3 reveals that APS $\ll K_{\mathrm{m}}$. Hence, we can neglect APS in the denominator. Thus the rate of assimilation $\left(\mathrm{k}_{\mathrm{a}}\right)$ can now be calculated as per Equation 5, the value is used in Equation 1.

$k_{a}=\frac{K_{e q 1} K_{e q 2} \cdot V_{\max }}{K_{m}}=1.86 \times 10^{-7} \mathrm{~s}^{-1}$

Before proceeding with a solution, there are a few unknowns that need to be defined. In Equation 1, whilst the density in the first bracketed term (passageway) is assumed to be that of air $\left(\rho_{\mathrm{I}}=1.225\right.$ kg. $\mathrm{m}^{-3}$ ), that within the leaf foliage (second bracketed term) is that of water $\left(\rho_{\mathrm{II}}=1000 \mathrm{~kg} \cdot \mathrm{m}^{-3}\right.$ ). The ratio of the two sulphur compound masses $\left(\mathrm{SO}_{2}\right.$ in region $\mathrm{I}$ and $\mathrm{SO}_{4}^{2-}$ in region II) is written as $\psi$ for convenience. Hence

$\psi=\left(\rho_{I} V_{I}\right) /\left(\rho_{I I} V_{I I}\right)$

The only unknown parameter in Equation 1 now is $b$, which is the feedback to the uptake of gaseous $\mathrm{SO}_{2}$ based on the current sulphur concentration within the leaf. In order to determine $b$, we use the permissible limit of sulphur content within the leaf $\mathrm{S}_{\max }$, which is 0.4 ppm. We argue that at this sulphur concentration, the net rate of $\mathrm{SO}_{2}$ influx into the leaf should be zero to counter the negative effects of high sugar concentration in the plant. Thus, we obtain the value of $b$ as:

$b=\frac{k_{c}}{s_{\max }}$

Having armed ourselves with the appropriate parameters we now return to Equation 1, which can be rewritten as:

$\int_{t_{0}}^{t} d t=\int_{s_{0}}^{s} \frac{d s}{\psi s_{g} k_{c}-\left(\psi s_{g} b+k_{a}\right) s}$

Integrating and rearranging for s, we get:

$S=\frac{\psi s_{g} k_{c}-\left\{\psi s_{g} k_{c}-\left(\psi b s_{g}+k_{a}\right) s_{0}\right\} \cdot e^{-\left(\psi b s_{g}+k_{a}\right)\left(t-t_{0}\right)}}{\psi b s_{g}+k_{a}}$

Equation 9 gives us the sulphur concentration (s) within the leaf at any time $(\mathrm{t})$ with the initial concentration of sulphur at time to being so. Note that we balance the net sulphur exchange for uniformity. This equation governs the sulphur concentration during daytime (8 AM to
$6 \mathrm{PM}$ ), when $\mathrm{SO}_{2}$ uptake is active. Uptake during the night is governed by the respective rate of uptake and ambient $\mathrm{SO}_{2}$ concentration.

Now that we know the sulphur content in the leaf as a function of time, the rate of $\mathrm{SO}_{2}$ uptake from the atmosphere can be obtained by substituting it into the first term on the right side of Equation 1. Thus,

$\frac{\partial m_{S O 2}}{\partial t}=\rho_{I} V_{I} s_{g} \cdot\left\{k_{c}-b s\right\}$

\subsection{Short term variation in leaf Sulphur content}

Fig. 5 represents a typical pattern of leaf sulphur concentration over 24 hours (8:00am - 6:00pm). During the day, $\mathrm{SO}_{2}$ is absorbed from the atmosphere, converted into sulphur and assimilated simultaneously. At night, the rate of uptake drops drastically as because of a fall in stomatal aperture and ambient $\mathrm{SO}_{2}$ levels. The time step has been taken to be 10 seconds.

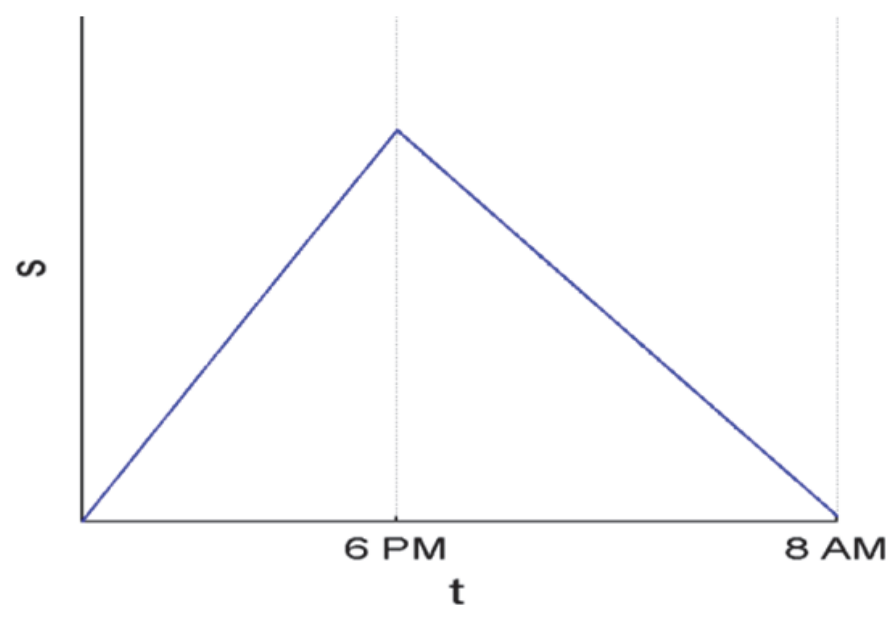

Fig. 5 A typical pattern of leaf sulphate content over a period of 24 hours.

\subsection{Different initial concentration of sulphur in leaves}

For the same ambient concentration of $\mathrm{SO}_{2}(10 \mathrm{ppb})$, the model is run for three different initial concentration of sulphate $\left(\mathrm{s}_{0}\right)$ in the leaf: case 1: $\mathrm{s}_{0}=10 \mathrm{ppb}$, case $2: \mathrm{s}_{0}=300 \mathrm{ppb}$, and case $3: \mathrm{s}_{0}=400 \mathrm{ppb}$ (upper limit of allowable sulphur content in leaves).

When the sulphur levels in leaves are low (case 1), the rate of uptake is much higher than the rate of assimilation. In fact, out of all the three cases, the increase in sulphur over the day is highest for case 1 (0.4 ppb) (see Fig. 6)

Now consider a point in time where the concentration has reached $300 \mathrm{ppb}$ (arbitrarily taken as the extreme concentration - much above the concentration for industrial areas) as in case 2 (Fig. 6). As the value of $\mathrm{s}$ increases, the rate of uptake drops with a simultaneous increase in assimilation. The trend is inverted in case 3 (Fig. 6), where over the 24 hours assimilation outweighs the uptake. Clearly, this points to an equilibrium concentration between $1 \mathrm{e}^{-8}$ and $3 \mathrm{e}^{-8}$, where over the day, the net uptake equals the net assimilation. This will be discussed in subsequent sections. Finally, for the maximum possible sulphur concentration, the uptake during the day falls to a value where it is balanced out (or overridden) by the assimilation. As usual, during the night, assimilation is the fastest out of all cases (see Fig. 6).

During the day, $\mathrm{SO}_{2}$ is absorbed from the atmosphere, converted into sulphur and assimilated simultaneously. At night, the rate of uptake drops drastically as because of a fall in stomatal aperture and ambient $\mathrm{SO}_{2}$ levels. 

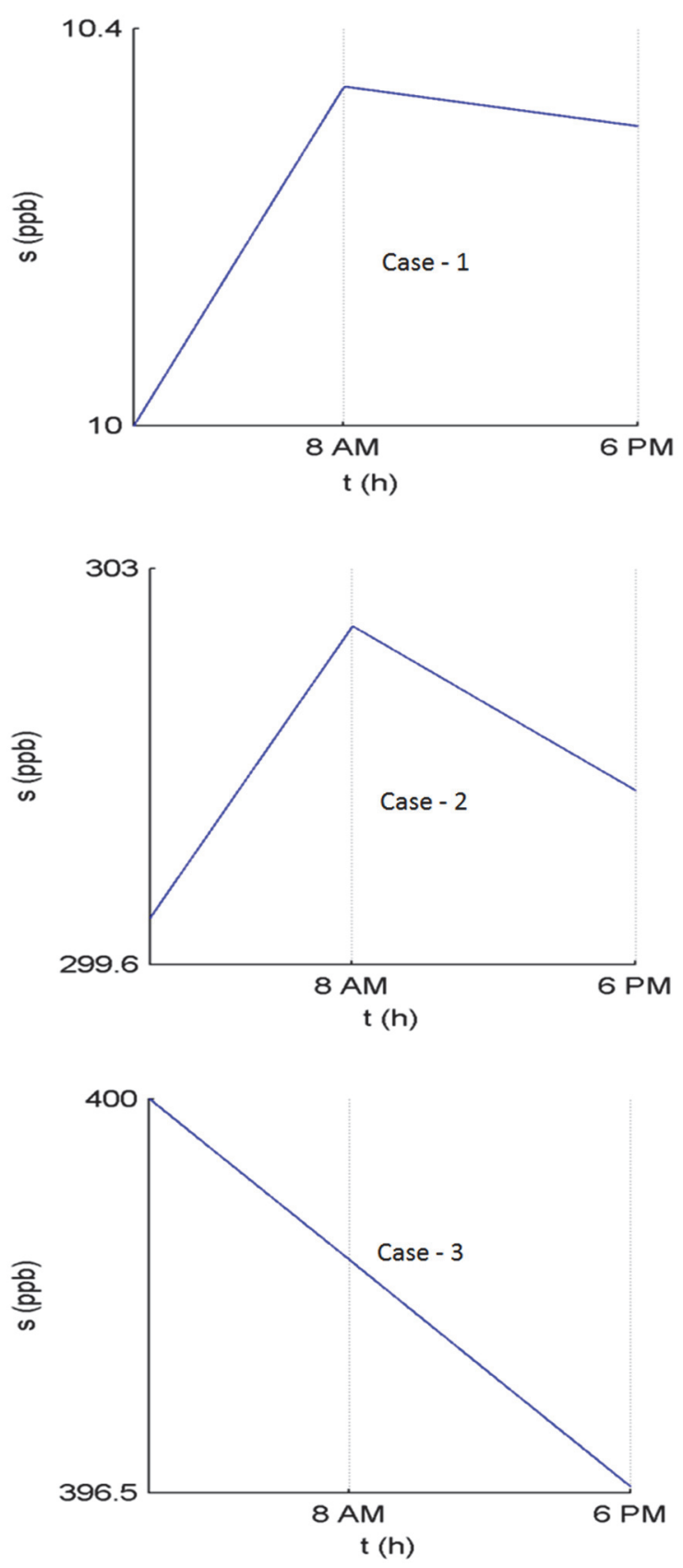

Fig. 6 Model response to different initial concentration of sulphate in leaves (Case 1, 2 \& 3). Lower initial concentration promotes uptake, while higher initial concentration causes assimilation to dominate.

\subsection{Long-term variations in leaf sulphur content}

We now analyze the time histories of leaf sulphur content for two different cases - Case 1 is at a regular urban neighbourhood with ambient levels of atmospheric $\mathrm{SO}_{2}$ in the range of $4 \mathrm{ppb}$ (night) to 10 $\mathrm{ppb}$ (day). Case 2 represents a heavily industrialized zone with ambient $\mathrm{SO}_{2}$ levels in the range of $40 \mathrm{ppb}$ (night) to $100 \mathrm{ppb}$ (day). However, the measured ambient concentration of $\mathrm{SO}_{2}$ inside the subway was in the range of $2 \mathrm{ppb}$ (day) to $0.5 \mathrm{ppb}$ (night). Apart from diurnal variation, the sulphur concentration pattern does not change with time. For both cases, the initial concentration of sulphur in leaves is assumed to be zero. The period of simulation is one calendar year.
Plants in industrial zones show a higher mean sulphur concentration $(150 \mathrm{ppb})$ in leaves as compared to those in low $\mathrm{SO}_{2}$ zones $(20 \mathrm{ppb})$ (see Fig. 7). To analyze temporal trends, a plot of normalized concentration versus time is plotted for both cases. It is observed, that even after concentration normalization, case 1 plants approach mean concentration levels faster, indicating that their normalized rate of uptake is also higher (Fig. 7).
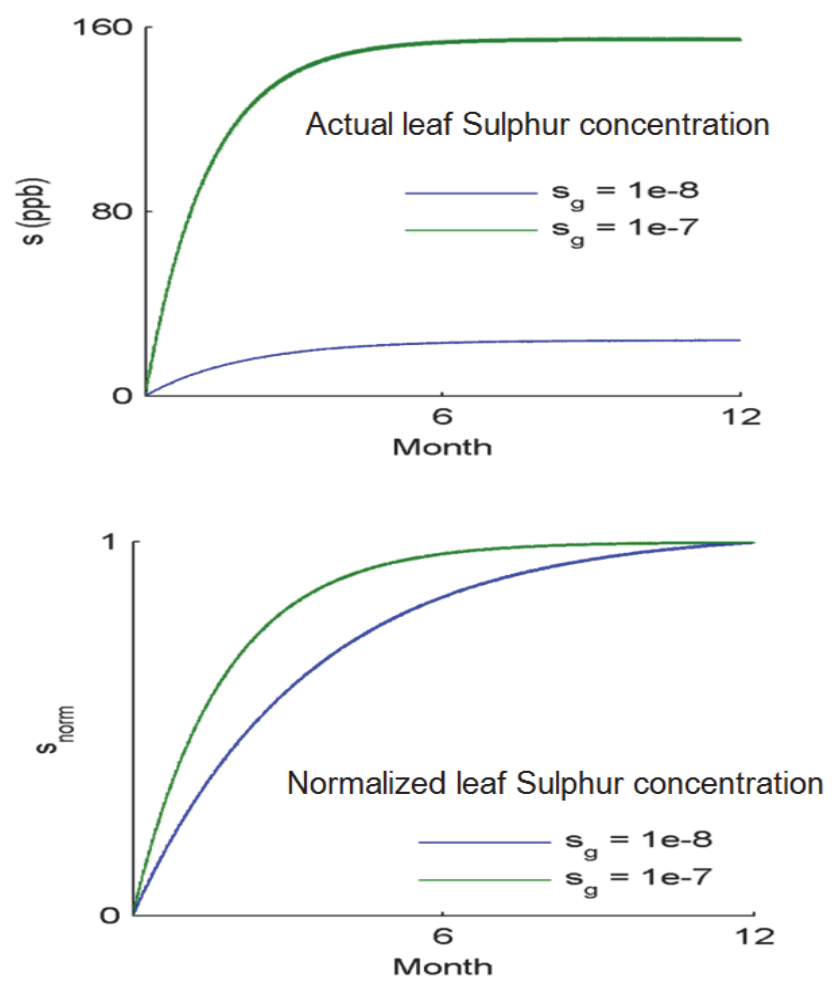

Fig. 7 Leaf sulphur concentration versus time for two cases of ambient $\mathrm{SO}_{2}$ concentration (10 ppb and $100 \mathrm{ppb}$ ). The latter case has higher mean sulphur concentration and faster normalized uptake rates.

\subsection{The mean leaf sulphur content as a function of ambient $\mathrm{SO}_{2}$ concentration}

For a given concentration of $\mathrm{SO}_{2}$ in the atmosphere, the mean sulphur content can be calculated by substituting $\mathrm{t}=\infty$ in Equation 9. Here, we use the mean value of $\mathrm{kc}$ i.e., the averaged value for day and night. This variation has been plotted for a range of sg values between $0 \mathrm{ppb}$ and $100 \mathrm{ppb}$ (Fig. 8).

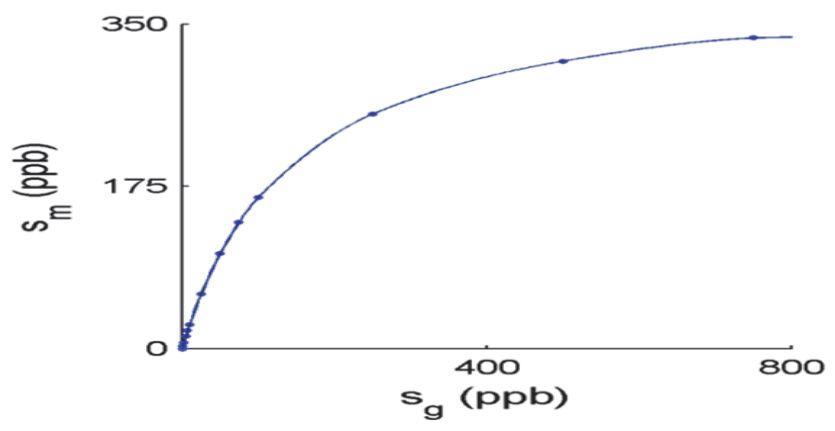

Fig. 8 Mean sulphur concentration versus ambient $\mathrm{SO}_{2}$ level - plotted for a range of Sulphur concentration in atmosphere $(\mathrm{sg})$ 


\subsection{Mass of $\mathrm{SO}_{2}$ absorbed}

Using Equation 10, we can find the mass of $\mathrm{SO}_{2}$ taken up by the façade. Fig. 9 highlights the mass of $\mathrm{SO}_{2}$ absorbed by the vegetated wall per day for a period of one year.

In order to ensure that only the steady state processes are applied, the initial value of $s$ is taken as the mean leaf sulphur concentration at that sg. Due to this, as shown by the plots ) see Fig. 10), the maximum change in sulphate content is successfully regulated to $5 \%$ fewer than the initial value of normalized mass uptake versus time. The variation in the total $\mathrm{SO}_{2}$ absorbed by the plant in a year with respect to the ambient $\mathrm{SO}_{2}$ concentration is as shown in Fig. 11.

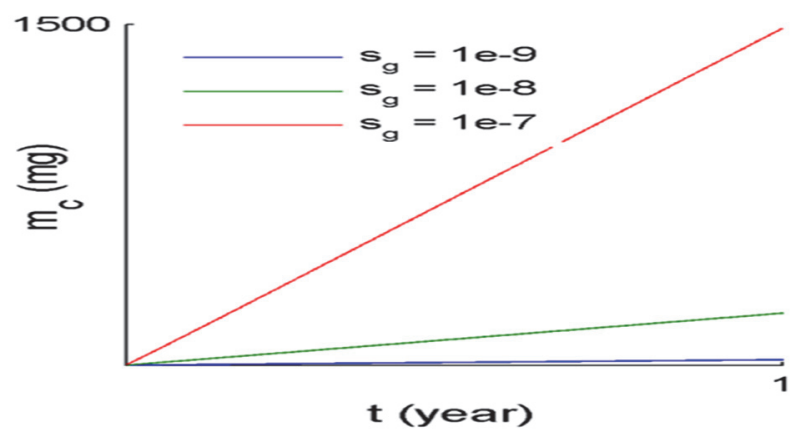

Fig. 9 Cumulative variation of mass of $\mathrm{SO}_{2}$ absorbed by the plant with respect to time - $\mathrm{sg}$ represents the $\mathrm{SO}_{2}$ concentration in atmosphere.

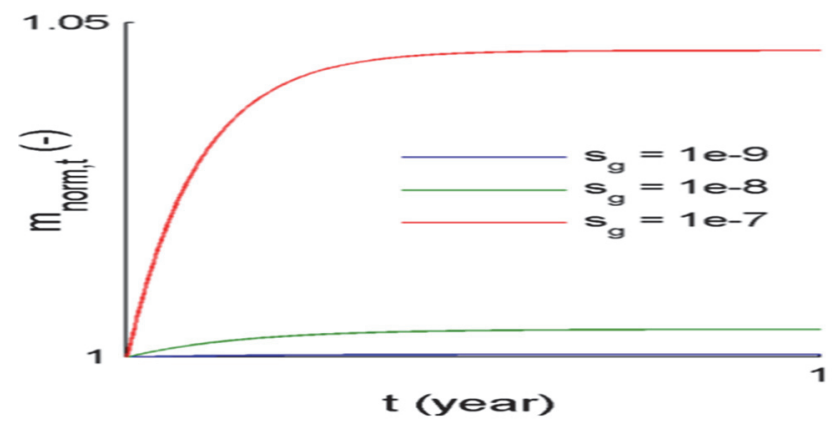

Fig. 10 Normalized variation in instantaneous mass uptake of $\mathrm{SO}_{2}$ with time. Note: due to appropriate selection of initial leaf sulphur concentration, the maximum change in the instantaneous $\mathrm{SO}_{2}$ uptake is restricted to less than $5 \%$.

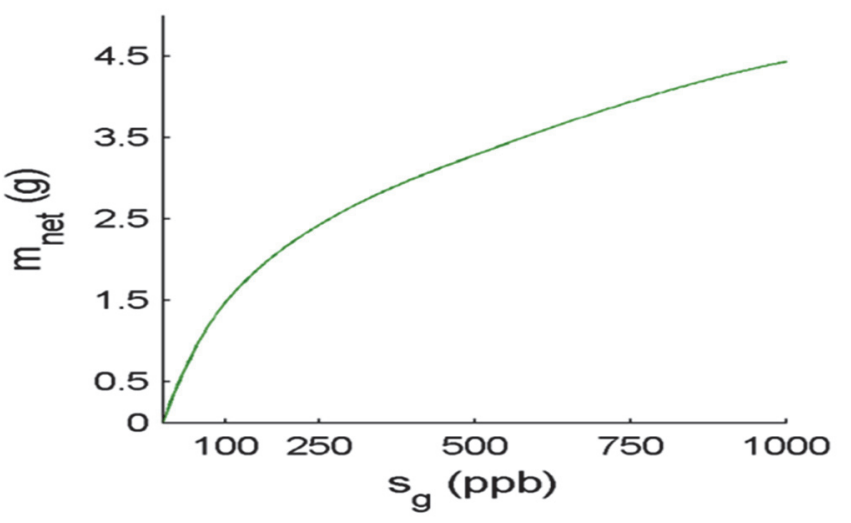

Fig. 11 Annual $\mathrm{SO}_{2}$ absorption versus ambient $\mathrm{SO}_{2}$ concentration
From Fig. 11, it is clear that gaseous $\mathrm{SO}_{2}$ is increasingly absorbed with the passage of time. This then triggers the reaction pathways discussed earlier, eventually leading to Sulphates $\left(\mathrm{SO}_{4}{ }^{2-}\right)$ formation in the leaf samples. Apart from $\mathrm{SO}_{2}$, Oxides of Nitrogen are also assimilated resulting in the formation of Nitrates $\left(\mathrm{NO}_{3}{ }^{-}\right)$. Sulphates and Nitrates present in the leaves, have a contribution from atmospheric gases. However, root mediated pathways also lead to the production of inorganic ionic constituents within the samples. The quantification of these pathways does not fall within the remit of this thesis. However, we have provided a full and detailed experimental quantification of all important ions - a final destination and culmination point of all sources - this has a more direct bearing on the overall cleansing efficiency of green structures.

\section{WIDER IMPLICATION AND CONCLUSION}

Green façades are efficient at removal of residual background pollution only. Nevertheless, residual background pollution is a big issue $-\mathrm{a}$ line source of pollution may leave its trail even when the source is turned off. Vegetated façades provide a medium of controlling the rate at which pollution pervades an environment, an urgent requirement in many metropolises. In this paper, we have elucidated the benign properties of Vernonia elaeagnifolia as a wall creeper with its ability to absorb suspended particulate matter, oxides of nitrogen and sulphur. The profusion of growth of this species promised to be a good solution for draping not just walls and roofs, but also walls of high rise buildings, which are mushrooming thick and fast in the resource starved nation of India. While sunshine is aplenty (averaging over 300 days a year), it is still severely underutilized. This first study combining the diffusive uptake modelling along with UV Spectrophotometric analysis of absorbed pollutants lucidly demonstrates the versatile creepers' cleansing efficiency.

\section{REFERENCES}

Arnon, D.I., and Stout, P. R., 1939, "The Essentiality of Certain Elements in Minute Quantity for Plant with Special Reference to Copper," Plant Physiology, 14(2), 371-75.

https://doi.org/10.1104/pp.14.2.371

Barker, A.V., and Pilbeam, D. J., 2007, Handbook of Plant Nutrition, Taylor and Francis group, CRC Press, New York.

http://vanveenorganics.com/ebooks/Handbook $\% 20$ of $\% 20 \mathrm{Plant} \% 20 \mathrm{~N}$ utrition.pdf

Bhargava, S. K., 2008, Practical methods for water and air pollution monitoring, New Age International private Ltd. India.

ISBN 13: 9788122424041

Blumberg, K. O., Walsh, M. P., and Pera, C., 2003, "Low-Sulfur gasoline and diesel; the key to lower vehicular emissions." ICCT -The International Council on Clean Transportation, 10 - 23.

http://www.unep.org/transport/pcfv/pdf/publowsulfurpaper.pdf.

Cardenas, N. R., Adamovicz, S., and Robin, P., 1997, "Diurnal Nitrate Uptake in Young Tomato plants: Test of a Feedback-based Model," Journal of Experimental Botany, 49, 721-730.

https://doi.org/10.1093/jxb/49.321.721

Gay, S. C., Fribourgh, J. L., Donohoue, P.D., Segel, I.H., and Fisher, A.J., 2009, "Kinetic Properties of ATP Sulfurylase and ATP Kinase from Thiobacillusdenitrificans," Archives of Biochemistry and Biophysics, 489, 110-117.

https://doi.org/10.1016/j.abb.2009.07.026

Haensch, R., Lang, C., Riebeseel, E., Lindigkeit, R., Gessler, A., and Rennenberg, H., 2006, "Plant sulfite oxidase as novel producer of 
H2O2: combination of enzyme catalysis with a subsequent nonenzymatic reaction step," Journal of Biological Chemistry, 281, 6884 6888.

https://doi.org/10.1074/jbc.M513054200

Jeff, L., and Wayne, L., 2010, Teaming with microbes, Timber press Inc, revised ed., Portland, Oregon.

ISBN 978-1-60469-113-9

Joshi, S. V., and Ghosh, S., 2014, "On the Air Cleansing Efficiency of Vegetated Green Walls: A CFD Analysis of Mechanistic Details of Transport Processes," Journal of Theoretical Biology, 361, 101-110. http://dx.doi.org/10.1016/j.jtbi.2014.07.018

Keener, J., and Sneyd, J., 2008, Mathematical Physiology: I: Cellular Physiology, $2^{\text {nd }}$ ed., Springer, NY.

http://www.fulviofrisone.com/attachments/article/412/mathematical \%20physiology.pdf

Konrad, M., Kirkby, E., Kosegarten, and Appel, 2001, Principles of Plant Nutrition, $5^{\text {th }}$ ed., Kluwer Academic Publishers, Dordrecht, Netherlands.

ISBN: 9781402000089

Kramer, U., 2012, Nutrient and toxin all at once: How plants absorb the perfect quantity of minerals, Department of Plant Physiology, Ruhr University, Bochum.

http://esciencenews.com/articles/2012/04/13/nutrient.and.toxin.all.on ce.how.plants.absorb.perfect.quantity.minerals
Lewcock, A., and Harriman, T., 2012, "New Light Shined on Photosynthesis," The Royal Society of Chemistry, Issue 2. http://www.rsc.org/images/Mole-March2012-Artificialphotosynthesis tcm18-214048.pdf.

Muralikrishna, K.V.S.G., 1997, Chemical analysis of water and soillaboratory manual, Reem publications private Ltd., India.

ISBN: 9788183510004

Owen, P. C., and David, K. E., 1989, Plant Analysis Handbook for Georgia, Co-operative Extension Service, College of Agriculture, University of Georgia.

$\underline{\text { http://aesl.ces.uga.edu/publications/plant/ }}$

Schuermann, P., and Brunold, C., 1980, "Formation of Cysteine from adenosine 5'-phosphosulphate (APS) in extracts from spinach chloroplasts," Z Pflanzenphysoil, 100, 257-268.

https://doi.org/10.1016/S0044-328X(80)80254-6

Suter, M., Von, B. P., Kopriva, S., Den, C. R. O., Schaller, J., Kuhlemeier, C., Schuermann, P., and Brunold, C., 1999, "Adenosine 5'-Phosphosulfate Sulfotransferase and Adenosine 5'-Phosphosulfate Reductase are Identical Enzymes," Journal of Biological chemistry, 275, 930-936.

https://doi.org/10.1074/jbc.275.2.930

Taiz, L., and Zeiger, 2002, Plant Physiology, $3^{\text {rd }}$ ed., Sinauer Associates, 68-69. ISBN 0-87893-823-0

http://exa.unne.edu.ar/biologia/fisiologia.vegetal/PlantPhysiologyTai z2002.pdf 